\title{
Exploring the Impact of COVID-I 9 Lockdown on Public Spaces through a Systems Modelling Approach
}

\author{
Nicholas Stevens \\ University of the Sunshine Coast, Australia \\ nstevens@usc.edu.au \\ Silvia Tavares \\ University of the Sunshine Coast, Australia \\ stavares@usc.edu.au
}

\begin{abstract}
This paper offers a Human Factors and Ergonomic \& Sociotechnical Systems (HFE \& STS) methodology to assist in the exploration and description of COVID-19 lockdown impacts on public spaces in Queensland, Australia. The approach utilises an existing before COVID - systems model of an archetype public space to identify activities that were restricted in public space, and how such restrictions affect system performance. First an overview of the HFE \& STS system modelling approach, Cognitive Work Analysis, is provided and we present the systems model of an archetype public space. Next, the range of lockdown restrictions on public space activity are identified in the model and the system's implications on community and individual wellbeing are explored. In conclusion, the necessity for new activities and functions of public space, post COVID-19, are reflected upon and considered from a systems standpoint.
\end{abstract}

Keywords: human factors and ergonomics, sociotechnical systems, urban design, COVID-19, public space

To cite this article:

Stevens, N., Tavares, S. (2020). Exploring the Impact of COVID-19 Lockdown on Public Spaces through a Systems Modelling Approach, The Journal of Public Space, 5(3), I9I-206, DOI

10.32891/jps.v5i3.1377

This article has been double blind peer reviewed and accepted for publication in The Journal of Public Space. (c) (1) \$) This work is licensed under a Creative Commons Attribution - Non Commercial 4.0 International License https://creativecommons.org/licenses/by-nc/4.0/ 


\section{New approaches to exploring urban complexity}

The dynamics of urban spaces are complex, and disasters exacerbate this complexity. Previous research has demonstrated the change in the nature of urban public spaces in post-disaster situations, when key desirable urban design outcomes - such as urbanity and vibrancy - become a source of fear. Urbanity is manifested through the combination of density and diversity, or the combination of the most diverse social things in the smallest space allowing for incidental interaction (Lévy, 1997). In the case of a disaster where density is an issue, urbanity is consequently compromised, and in these cases the design of urban spaces has to consider aspects of built form not previously favoured (Tavares et al., 2019). An example is the consideration of variations of levels of urbanity (Lees, 2010; Van Diepen \& Musterd, 2009), allowing for different levels of interaction through the design of urban social spaces and urban retreat spaces. To explore such possibilities for the design of novel and new urban spaces it is useful to extend current thinking and perhaps look to disciplines with a legacy of human interaction and safety critical research.

The use of Human Factors and Ergonomics \& Sociotechnical Systems (HFE \& STS) approaches in the design and development of urban form is an emerging paradigm (e.g. Patorniti et al., 2018; Stevens, 2016), demonstrating the recognition that HFE \& STS viewpoints are aligned to those of urbanism and urban development. Both sets of disciplines are concerned with the human condition and the interface between people and their environments. HFE \& STS approaches seek to jointly optimise the socio (of people and society) and technical (non-human) aspects of our environments (Walker et al., 2008). They are used extensively in a range of complex and safety critical domains, for example computer science (e.g. Bisantz et al., 2003); road safety (e.g. Cornelissen et al., 20I3); disaster management (e.g. Jenkins et al., 20l0); and aviation (e.g. Salmon, Walker, et al., 2016). While new to urbanism, they have much to offer in the exploration of the inherent complexity of our cities. Such approaches permit a systems examination of the range of interdependent activities and competing demands of our urban world view (Stevens et al., 2018).

This paper details the use of an existing (pre-COVID) HFE \& STS model of 'ideal public space' (Stevens \& Salmon, 20I5) to explore the implications of COVID- 9 lockdown on community and individual health and wellbeing. The model was created to represent universal design template of public spaces which supports and promotes a healthy and happy community; an inclusive and connected community; and a healthy and active individual. This model is employed as an archetype baseline, and the 2020 Queensland (Australia) lockdown limitations are then imposed on the public space activities presented within it. The implications of limiting those activities are then revealed in the overall system performance. The Queensland Level 3 lockdown limitations represent work and study from home orders, travel distance restrictions, the closure of all non-essential service industries, food and beverage businesses and hotels only offer takeaway service, grocery stores remain open with capacity limits (Queensland Government, 2020). During Level 3 restrictions people are permitted to move freely within their neighbourhoods and evidence suggests the use of local parks and public spaces increased (ABC, 2020). Whilst public spaces are in demand and largely accessible (physical distancing of 2 metres applies) authorities limited access to the recreational and public amenity infrastructure within them. Despite this curtailed capacity, the important functions and contributions of public space to social wellbeing and physical and mental health have never been in more demand. This study aims to better understand the impact of these 
restrictions on the use of public spaces and its urbanity. Any limits to access of parks and green spaces are already anticipated to be detrimental for the community (Freeman \& Eykelbosh 2020), as well as the reduced social connections provided by urban encounters, which is a consequence of urbanity itself (Montgomery, 1998).

A detailed overview of the systems approach, model development and methods is provided next; followed by the consideration and implications of Queensland Level 3 restrictions on the model. In the discussion section the consequences for public space design and use are explored; as well as the efficacy of HFE \& STS systems approaches for investigating the inherent complexities of public space.

\section{Methods - Cognitive Work Analysis (CWA) \& Work Domain Analysis (WDA)}

Cognitive Work Analysis (CWA) is a well-established HFE approach and was originally developed at the Risø National Laboratory in Denmark (Rasmussen et al., 1994). A key strength of CWA is its formative nature which provides a description of what could happen in the design of a complex system, rather than the more common normative analyses of what should happen (Vicente, 1999).

CWA and its first phase Work Domain Analysis (WDA) have been increasingly applied to examine a range of complex urban systems. These include, for example, transport land use integration (Salmon, Read, et al., 2016); active transport corridors (Stevens et al., 2018); and smart cities (Stevens et al., 2019). The sociotechnical and formative nature of the approach has allowed for the identification and optimisation of the emergent human behaviours and actions that occur (purposefully and accidently) within urban settings by virtue of the quality of their design. It offers new insights for urban design which present the possibilities for change, rather than the characteristic approach of limiting choice and enforcing controls on action.

CWA consists of five phases (Table. I), with a gradual transition from describing system elements to cognitive considerations - working from the environment and layout, to goals and context, to human behaviors (Jenkins et al., 2009; Vicente, 1999). WDA is often used as an independent method to provide detailed descriptions and analyses of complex sociotechnical systems (see Jenkins et al., (2009).

Table I. Five phases of Cognitive Work Analysis (adapted from Vincente, 1999).

\begin{tabular}{l|l} 
Phase & Tools used \\
\hline $\begin{array}{l}\text { I. Work Domain Analysis (WDA) } \\
\text { Identifies the constraints on behavior that are imposed by the physical context } \\
\text { and defines the environment that activity is conducted in (What, How, Why) }\end{array}$ & $\begin{array}{l}\text { Abstraction } \\
\text { Hierarchy } \\
\text { (AH) }\end{array}$ \\
\hline $\begin{array}{l}\text { 2. Control Tasks Analysis (ConTA) } \\
\text { Addresses constraints on activity imposed by events (How, By Whom) }\end{array}$ & $\begin{array}{l}\text { Decision } \\
\text { Ladder }\end{array}$ \\
\hline $\begin{array}{l}\text { 3. Strategies Analysis } \\
\text { Addresses various ways of approaching the same activity and the way } \\
\text { constraints influence the activity (How) }\end{array}$ & $\begin{array}{l}\text { Information } \\
\text { Flow Map }\end{array}$ \\
\hline $\begin{array}{l}\text { 4. Social \& Organization Cooperation Analysis (SOCA) } \\
\text { Addresses constraints imposed by roles and structures in place and different } \\
\text { factors may work together (How) }\end{array}$ & $\begin{array}{l}\text { All of the } \\
\text { Above }\end{array}$ \\
\hline $\begin{array}{l}\text { 5. Worker Competencies Analysis (WCA) } \\
\text { Addresses constraints by user behavior within the environment and what is } \\
\text { required (What) }\end{array}$ & $\begin{array}{l}\text { Skills Rules } \\
\text { Knowledge }\end{array}$
\end{tabular}


Of interest specifically for this paper was the development, in 2015 , of a systems representation of urban public space utilising WDA (Stevens \& Salmon, 20I5). That study involved the development of a systems model of an archetype or 'ideal' public space that sought to achieve the 'inclusive public space for all' concept, regardless of an individual's cognitive or physical ability. The aim was twofold: first, to showcase the utility of using HFE systems analysis methods such as WDA in urban design applications. Second, to provide a public space design model that made explicit the complex interactions afforded when seeking to incorporate subjective and objective outcomes, such as inclusiveness, health, safety, engineering, and sensory design.

The model was developed to be representative of a range of suburban park and inner urban public space typologies. Specifically, those public spaces developed in the tradition of post $19^{\text {th }}-20^{\text {th }}$ Century anglo-colonial urban form, represented strongly, for example, in the cities of Australia, New Zealand and the United States. Figure I. For this study, we have operationalised the existing 2015 model as a pre-COVID baseline for the review of the lockdown implications on public space in Queensland, Australia.
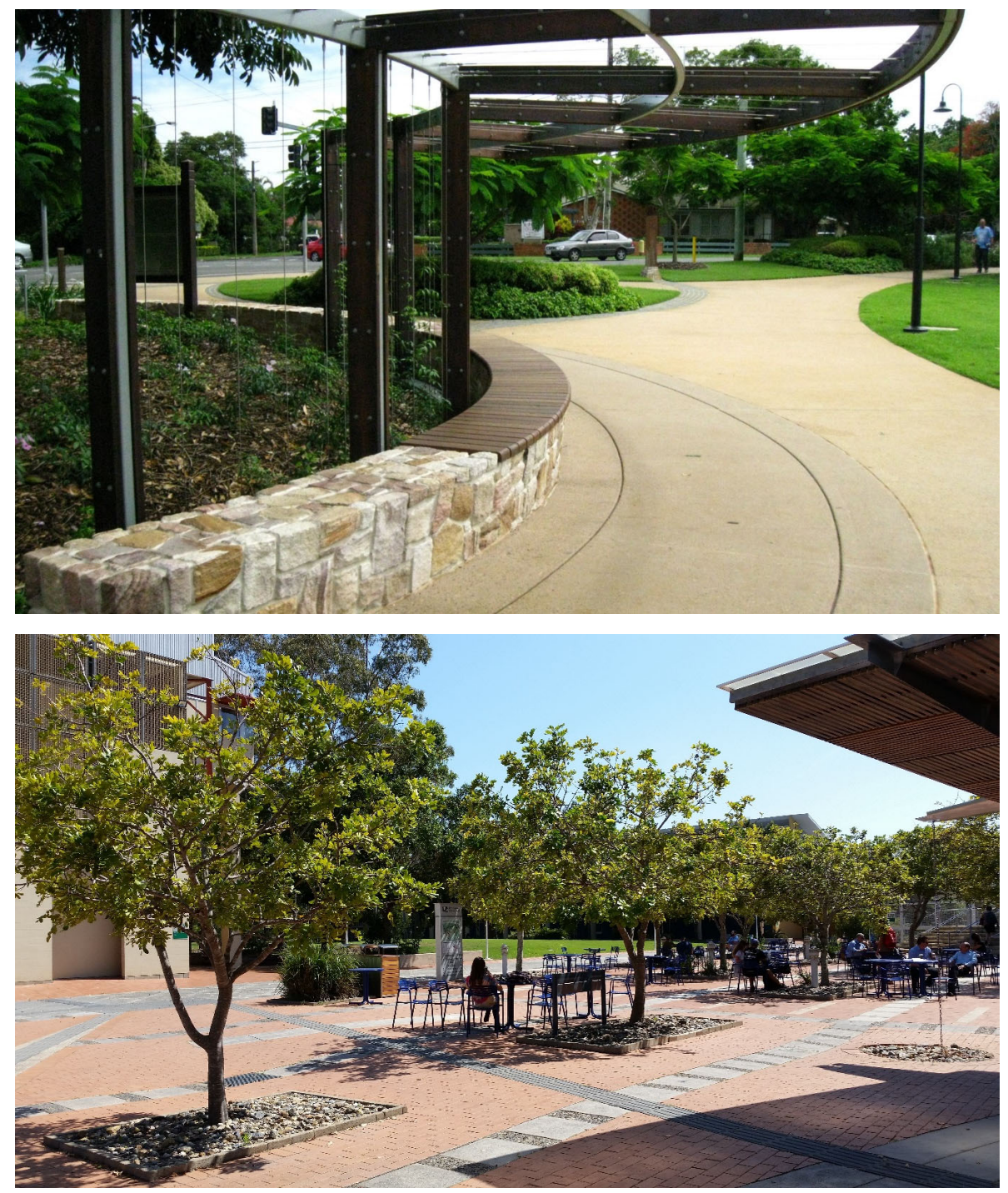

Figure I. Typical suburban park and inner urban public spaces (Source: Authors). 


\section{Work Domain Analysis (WDA)}

WDA can be used to model complex (urban) sociotechnical systems by describing them from their overall intended purposes, the activities that are undertaken within them, to the range of resources available to the system. The method involves constructing an Abstraction Hierarchy $(\mathrm{AH})$ of the system in question which provides an event and actor independent description of it. That is, a WDA is not concerned with contextual issues - e.g. night and day, seasonality or weather - it is simply describing and defining the domain, in this instance public space. This does not make WDA any less useful, as it allows for a comprehensive and complete description of the system (work) in addition to the environment within which this occurs (domain) (Naikar, 20I3).

The WDA models the system across five (5) levels of abstraction; here to describe an archetype urban public space. The levels include:

I. Functional purpose - The overall purpose(s) of the system. E.g. an inclusive and connected community.

2. Values and priority measures - The criteria the system uses for measuring progress towards its functional purpose. E.g. maximise safety.

3. Purpose related functions - The general functions or activities within the system required for it to achieve its functional purpose. E.g. allow social Interaction.

4. Object related processes - The processes associated with the physical objects within the system. E.g. surfaces for sitting.

5. Physical objects - The physical objects and resources within the system that afford the required processes. E.g. seating.

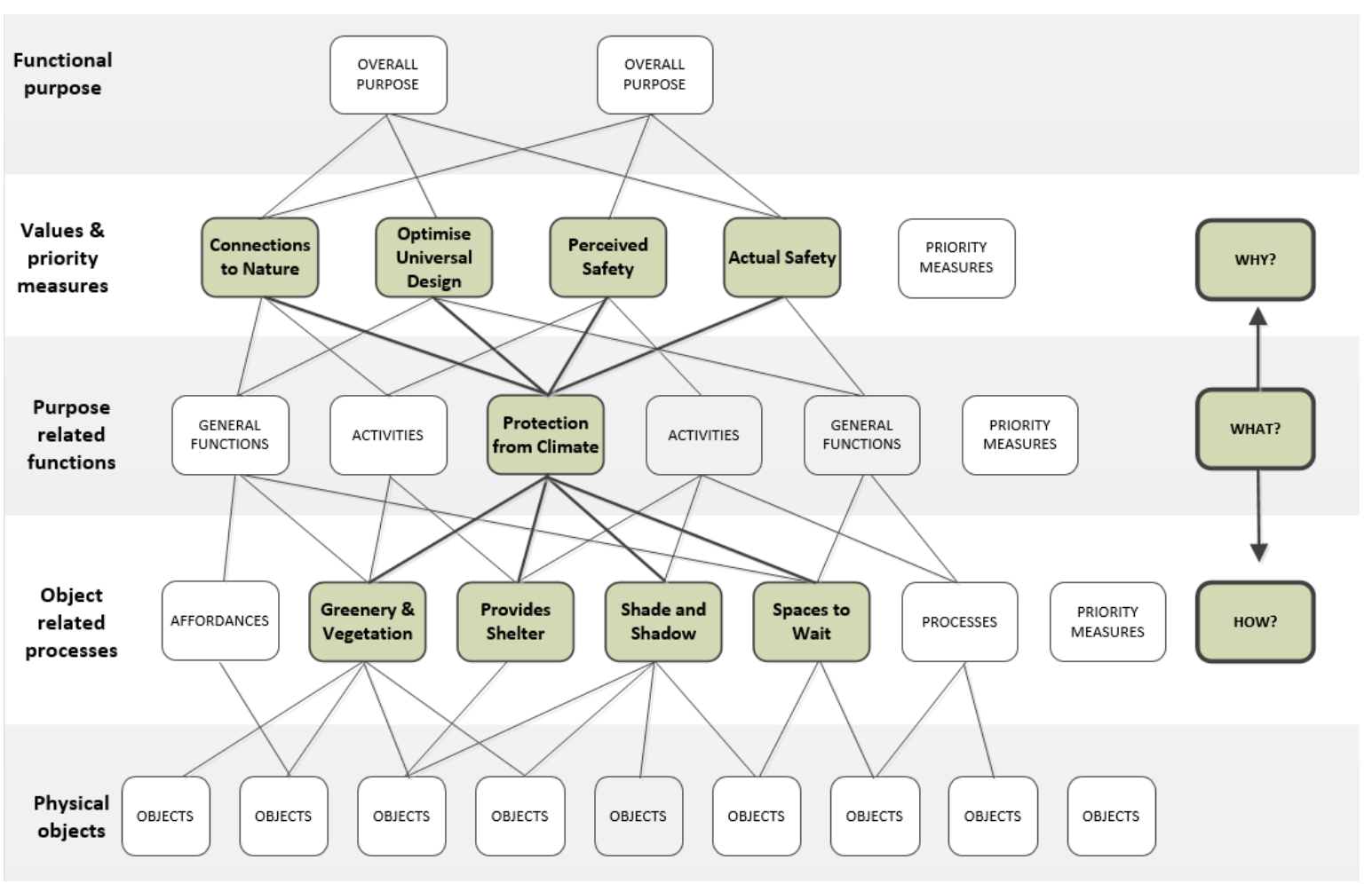

Figure 2. Work Domain Analysis levels of abstraction \& means-ends relationships (Source: Authors)

The output provides a model of what activities can be performed within a system, but also how and why they are performed and with what. Through a series of 'means-ends' 
links it is possible to model the what, why and how interactions of the system components and the influence this has on overall system performance. That is if a single node is explored in the model, the links it has to the level above identify why this node is necessary, and the links below represent how it is achieved (Figure 2). These links are not weighted but simply represent a relationship between the nodes at each level. They indicate that the operation of the system will follow these pathways and have these interactions and interdependencies in its operation.

The following is a condensed eight-step approach for the development and establishment of a WDA. The following overview provides both a general description of the method, and detail on the approach taken to establish the public space model used in this study (Stevens \& Salmon, 2015).

Step one: define the system and establish aims

Clearly define the system under analysis and establish the aim of the project. Consult with end users and subject matter experts (SMEs) to discuss the aims and expectations of a project.

The public space WDA aimed to establish an archetype which drew together current literature and leading practice approaches to build an indepth and integrated understanding of accessible, engaging and inclusive public space.

Step two: anticipate project constraints

Consider any logistical and financial constraints which may impact the scope of the WDA. Overcoming schedule and funding-based constraints necessitates a well-defined and realistic project timeline, budget and careful management.

Step three: define the system boundary

The analytical boundary of the system under analysis must be defined. It should be broad enough to capture the system in detail yet narrow enough to remain manageable. Whilst acknowledgeing that no system operates in isolation, it is important to be able to imagine the focus of analyses as discrete. For example, published case studies of urban systems using WDA have included footpaths (Stevens \& Salmon, 2015); playgrounds (Missen et al., 2017); and main streets (Patorniti et al., 20I8).

Step four: locate data sources

Identifying and utilizing a range of data sources to develop the model is necesarry (Naikar et al., 2016). They may typically include document review (e.g. standards, guidelines or technical manuals), academic literature review and analyses, case study observation, and interviews or focus groups with SMEs.

The public space WDA model presented has considered and included, where appropriate, the academic literature on walkablity (Ewing \& Handy, 2009; Gray et al., 20I2); inclusive public space and urban design (Low et al., 2009; Burton et al., 2006); and sensory urban design (Abedi et al. 20II; Degen \& Rose, 2012). Further it reviewed the 7Senses design framework (http://www.7senses.org.au/); drew upon the resources of Project for Public Spaces (https://www.pps.org/); and considered guidelines for public space design from government (Australian Government, 20I2; Victorian Government, 20I4). The WDA was developed and refined by five SMEs from the disciplinary fields of landscape architecture, urban design, public health, community development and human factors. Two of the analysts had previously developed WDA models in urban design 
contexts, whilst another has extensive experience of developing systems models across a range of domains including defence, road and rail transport.

Step five: construct the WDA

The WDA is systematically developed by the analysts through the inclusion of keyword 'nodes' at each level. There is a software tool available for the development of the WDA, and for CWA more broadly (Jenkins et al., 2009). It is often appropriate to document a 'data dictionary' as a table of terms to allow for the more detailed description and attribution of the included nodes. Once the functional purposes and values and priority measures are described, it is generally easier to include the types of physical objects and purpose-related functions required. Table 2 provides a series of prompts for inclusions at each of the WDA hierarchy levels.

Table 2. Example WDA prompts (see also Naikar et al., 2016)

\begin{tabular}{lll}
\hline WDA hierarchy & Prompts & Key words \\
\hline Functional Purpose & $\begin{array}{l}\text { For what reasons does the } \\
\text { system exist? }\end{array}$ & $\begin{array}{l}\text {-purpose, goals, aims, objectives, } \\
\text { rationale. }\end{array}$ \\
\hline Values and Priority Measures & $\begin{array}{l}\text { What criteria establish if the } \\
\text { work domain is achieving its } \\
\text { purposes? }\end{array}$ & $\begin{array}{l}\text {-measures, results, targets, laws } \\
\text { and regulations, standards, criteria. }\end{array}$ \\
& $\begin{array}{l}\text { What functions are required } \\
\text { to achieve the purposes of } \\
\text { the work domain? }\end{array}$ & $\begin{array}{l}\text {-function, roles and responsibilities, } \\
\text { maintenance, tasks, activities. }\end{array}$ \\
& $\begin{array}{l}\text { What processes are the } \\
\text { physical objects in the work } \\
\text { domain used for? }\end{array}$ & $\begin{array}{l}\text {-uses, components, processes, } \\
\text { limitations, capacity, }\end{array}$ \\
\hline Object-Related Processes & $\begin{array}{l}\text { What are the physical objects } \\
\text { or resources - both human- } \\
\text { made and natural? }\end{array}$ & $\begin{array}{l}\text {-tools, equipment, infrastructure, } \\
\text { fittings, facilities, layout, buildings, } \\
\end{array}$ \\
\hline Physical Objects & & \\
\hline
\end{tabular}

Step six: refine the analysis

To refine the analysis and establish the links between nodes across each level the 'means-ends' approach is used. The means-ends links are informed by a series of 'howwhat-why' relations (Figure 2). This is an iterative process and not only helps establish links between nodes but assists in establishing if nodes are correctly located at a particular level of the WDA model.

Step seven: review and validation of the WDA

Draft WDA models is reviewed by appropriate SMEs. Often in a workshop, SMEs are asked to focus on each node within the model. SMEs may be first asked if nodes are appropriate, and second to identify any missing nodes. Third, SMEs may review the links between the nodes via means-ends enquiries of what, why and how. Naikar (2016) 
highlights that this review by SMEs is also an appropriate strategy for validating the work domain model.

A draft of the public space model was constructed by the urban design and public health practitioners, which was reviewed by all experts at an analyst workshop. Any disagreements about the inclusions or the linkages between levels of model were resolved through discussion until consensus was met.

Step eight: detailed domain analyses

Following the completion of the WDA model, depending on the aim and purpose of the project, it is often useful to use the analyses for either the assessment of existing systems, or to inform the design of proposed systems. The 'before COVID' baseline public space.

\section{The 'before COVID' baseline public space}

The establishment of this systems model of public space was a cooperative research project undertaken in South-east Queensland, Australia in 2015. The result was a WDA which modelled and described inclusive public space whose overall purposes were focused on community and individual wellbeing. Purposes which we would argue underpin the design and establishment of all public space. An overview of each of the levels of the 'before COVID' baseline public spaces model are presented, beginning at the top of the abstraction hierarchy. Following this, the approach undertaken to review the Level 3 lockdown restrictions on the model are detailed.

\section{The functional purpose}

The overall 'functional purposes' of public space were identified as 'a healthy and happy community'; 'an inclusive and connected community'; and 'a healthy and active individual' (Figure 3). It is important to note that, despite often being considered as the 'purpose' of public space, it is not at this level of the model where activities such as 'places to meet' are identified. The WDA permits a higher system understanding of such spaces, and when reflecting on their emergent influence with urban settings it is the community and individual purposes of health and wellbeing that are paramount.

Values and priority measures

The 'values and priority measures' support the ways in which the system achieves its purposes, and these are often quantifiable. For example, for all fourteen (I4) measures identified in this model (Figure 3), it is possible to establish data to support their progress. From the inclusion of 'engaging design elements', through to 'community connections and values' and 'actual safety' metrics are feasible. This is often assisted by reviewing the purpose-related functions, or activities, on the level below - remembering that the connected elements below always tell us how a specific node above is achieved. 


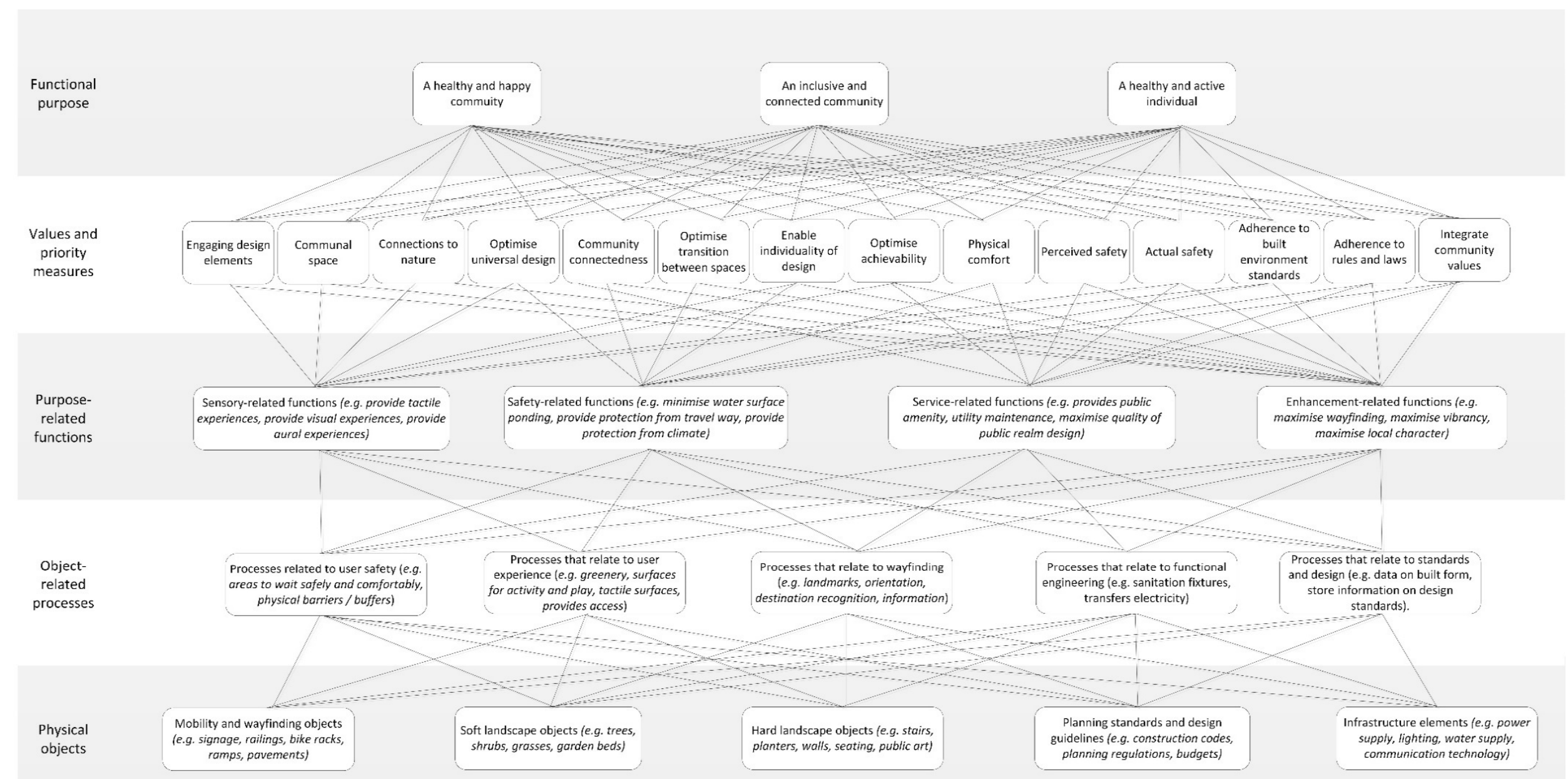

Figure 3. WDA model of archetype public space (Source: Authors

The Journal of Public Space, 5(3), 2020 | ISSN 2206-9658 | 199

City Space Architecture / UN-Habitat 
Exploring the impact of COVID-19 lockdown on public spaces through a systems modelling approach

\section{Purpose Related Functions}

Public spaces are complex places and this model has established that there are 25 different purpose-related functions (functions) that are necessary for the system to achieve its values and purposes above (Figure 3 ). In this project it was possible, and useful to aggregate or summarize the primary categories. These included sensory-related functions (e.g. provide tactile experiences, provide visual experiences, provide aural experiences); safety-related functions (e.g. minimise water surface ponding, provide protection from travel way, provide protection from climate); service quality related functions (e.g. provides public amenity, utility maintenance, maximise quality of public realm design); and user enhancement-related functions (e.g. maximise wayfinding, maximise vibrancy and urbanity, maximise local character) (Stevens \& Salmon, 20I5).

This level of the WDA is perhaps the most significant in that these functions (or activities) within the system link the more strategic, goal-oriented levels above it; with the physical resources and processes on the levels below. Any restriction upon the activities at this level have direct implications for the attainment (and diminished levels) of community and individual wellbeing at top of the system.

\section{Object Related Processes}

Individually in the model these nodes represent the 'object related processes' afforded by the physical resource in the level below. For example, 'provide shade and shadow', is a process which may be afforded by shelters, trees, or adjacent built form. Or, 'provides surface for objects' is an affordance of, pavement surface, fences, lawn, tables, and seating. This notion that a process can be acquired from multiple resources is important for resilience and flexibility in the design of public space. For efficiency in presentation the forty-seven (47) object-related processes have been aggregated (Figure 3). Those that relate to user safety (e.g. areas to wait safely and comfortably, physical barriers / buffers); user experience (e.g. greenery, surfaces for activity and play, tactile surfaces, provides access); wayfinding (e.g. landmarks, orientation, destination recognition, information); functional engineering (e.g. sanitation fixtures, transfers electricity,) and; standards and design (e.g. data on built form and land use, store information on design standards).

\section{Physical Objects}

The identification of the 'physical objects' and resources within the system is intended to be comprehensive. So, while it will include all elements that may be anticipated within public spaces - soft landscape (e.g. trees, shrubs, grasses, garden beds), hard landscape (e.g. stairs, seating, pavements) - it will also include those resources that are critical to operation but exist away from the space itself. For example, planning and engineering standards, design guidelines, maintenance budgets, rules and laws; all of these resources have intrinsic influence on public space, and it cannot effectively achieve its functional purposes without them. Important to acknowledge for exploring complexity and for optimising design is that a single resource can also afford multiple processes. A tree, for example, provides greenery, fruit and flower, shelter, shade and shadow, it is a landmark, and if endemic to the area offers both habitat and cultural knowledge. The fifty-five (55) physical objects included within the model of archetype public space have also been broadly categorised (Figure 3 ). 
Identifying the lockdown impacts on activity

To assist in determining the lockdown impacts, the authors reviewed each of the twentyfive (25) purpose related functions (public space activities) at the middle level of the WDA. They considered, first the requirements of the Level 3 lockdown, and then individually made a determination if this would effect each activity in turn. It was agreed that for this exploratory analyses that the lockdown measure either did, or did not, impact the activity. There was no partial determination. The authors then met to compare their results, and any variation between them was discussed until consensus was met. In addition, local case studies of park and public space settings were observed for a clearer determination of the lockdown restrictions (Figure 4).
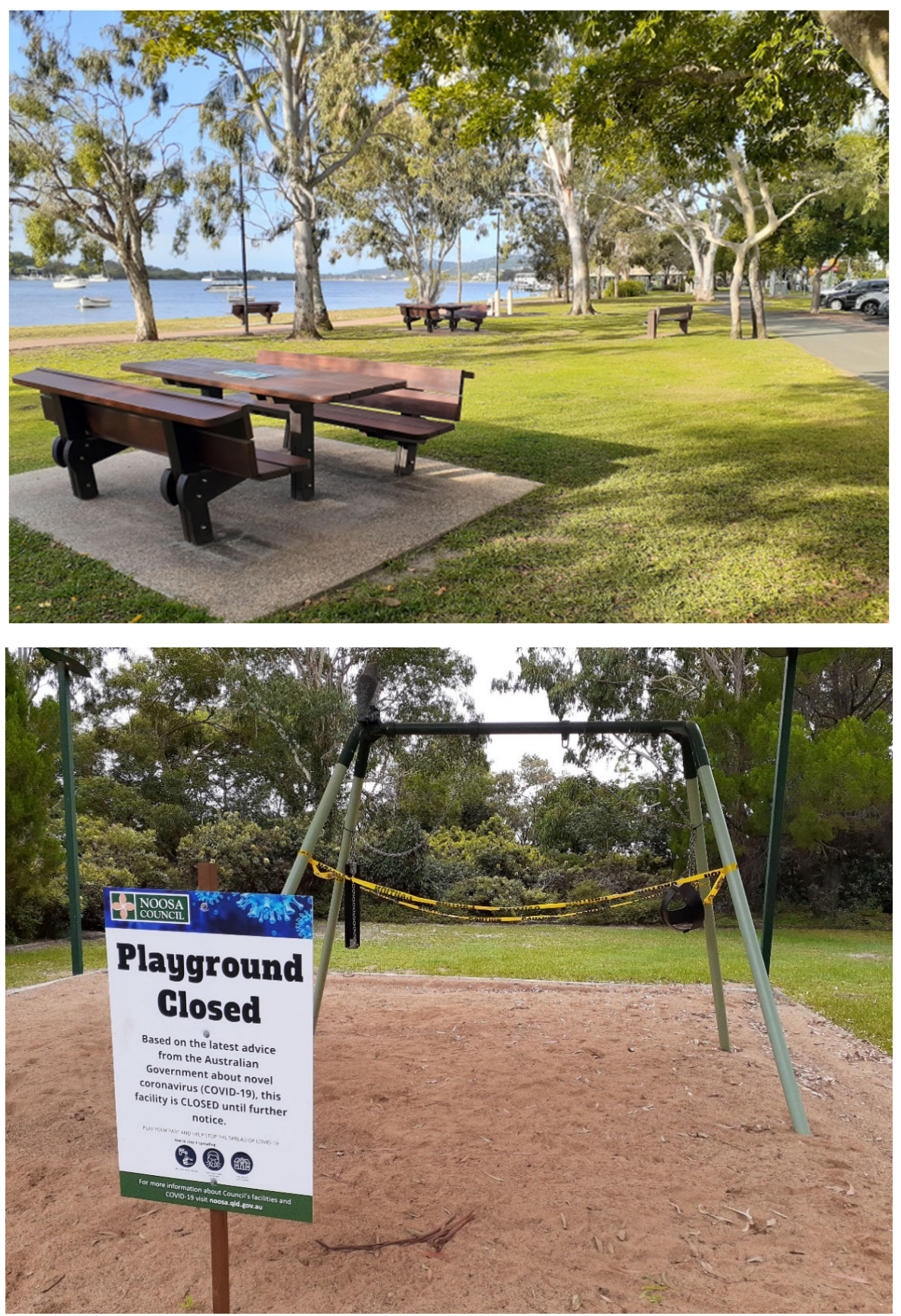

Figure 4 Public spaces under lockdown in Queensland (Source: Authors) 


\section{What does the model tell us about COVID lockdown?}

This pre-COVID baseline model of inclusive public space reveals that the overall functional purposes are principally related to community and individual wellbeing. That is, at the highest level, the purpose of public space is to contribute to: a healthy and happy community; an inclusive and connected community; and a healthy and active individual. The model also identifies that there are fourteen (14) measures which support and allow for the achievement of those purposes. Perhaps most importantly it identifies that there are twenty-five (25) purpose related functions, or activities, that are necessary for optimal system performance and attainment of the overall purposes. From a systems viewpoint of interdependence it follows that if any of these elements are diminished or missing, there is deterioration across the entire system.

In Australia, and nearly every country, COVID- 19 lockdown restrictions limited activity in public spaces. The use of this WDA model allows new insights into the knock-on effect of those restrictions for individuals and the broader community. This analysis will focus on the top three levels of the model as a way to demonstrate the efficacy of the systems approach. These levels provide the ability to succinctly explore the higher order implications of the COVID-I 9 lockdowns on public space. When undertaking analyses using WDA it is also possible, and useful, to consider the impacts from the physical objects level at the bottom. These types of design reviews consider the system implications of absent physical objects within a setting. Interestingly for this case study, even under lockdown many of the objects remain largely unchanged - it is the access to them via activities which has degraded the system. As such this analysis begins at the purpose related functions level, where these activities are first identified. Then by tracing the connections up the model it is possible to identify the links which are broken and therein how the loss of the public space activity undermines the values and therein, how the three overall purposes are also impacted.

Table I, represents the relationships between all twenty-five (25) purpose related functions (functions) on the $x$ axis; and all fourteen (I4) 'values and priority measures' on the $y$ axis. It identifies the established connections from the archetype WDA, and indicates via shading the fifteen (I5) functions that ceased under Level 3 COVID-19 lockdown in Queensland, Australia.

Which public space functions were impacted in lockdown

The function of providing 'public amenity', in the context of sanitation facilities, was no longer available, however also largely not required. It was however reported in some instances the closure of these facilities did have adverse outcomes for the homeless, and still diminished the measure of physical comfort and the capacity for communal space. Each of the five (5) functions associated with access to sensory experiences within public spaces were also unavailable to the community. These functions are recognised as underpinning some of the core values in public space including community connectedness, physical comfort and connections to nature. The four (4) prominent functions of public space which offer the individual and community access to 'local character', 'vibrancy', 'diversity', and 'fun \& adventure' also ceased. Further it was identified that the capacity for meaningful 'local ownership \& agency' generated via quality public space also ceased under lockdown. Perhaps most significantly, the activities associated with people interacting with each other were limited and often 
prevented - 'places to meet and wait'; 'active \& passive social interaction'; and 'community \& civic functions'.

The implications of removing these functions from public space may be explored in a systems sense by considering the dependencies between them and the measures they support. Of importance to note is that each function is connected to multiple measures, supporting different ways of how that measure is achieved. For example, the model establishes that the measure of perceived safety is supported and achieved via the functions of 'minimise traffic speeds', 'acknowledge seasonal changes', 'maximising vibrancy and urbanity', 'provide places to meet and wait', 'protection for the travel way', 'optimise the use of obstacles', 'optimise walkability and mobility', and 'optimise way finding'. In this example only the 'maximise vibrancy and urbanity' and 'provide places to meet and wait' functions have been lost via lockdown. The other functions remain in the system as they still support the public space even without the human interface. To take a functions perspective, on average, each removed function connects to and supports six (6) measures, with 'provides public amenity' the least linked function with four (4) connections, and 'active and passive social interaction' the most connected supporting eight (8) of the fourteen (14) measures.

Table 3. Values \& priority measure and purpose related functions relationships, and COVID-19 impacts

\begin{tabular}{|c|c|c|c|c|c|c|c|c|c|c|c|c|c|c|c|c|c|c|c|c|c|c|c|c|c|}
\hline $\begin{array}{l}\text { O shows a relationship between elements } \\
\text { shading shows the relationship is lost }\end{array}$ & 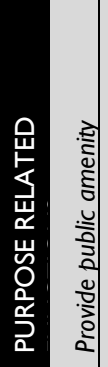 & 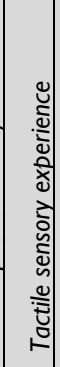 & 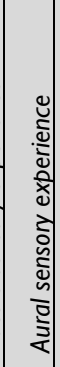 & 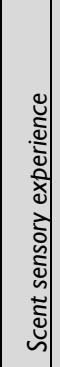 & 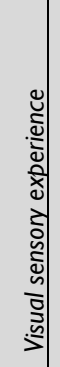 & 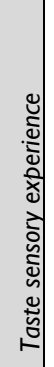 & 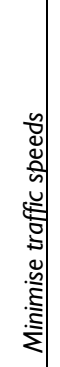 & 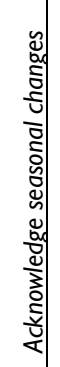 & 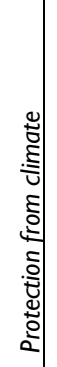 & 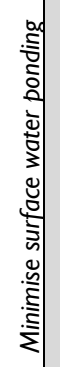 & 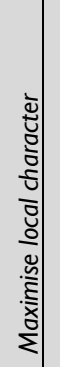 & 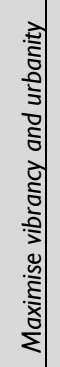 & 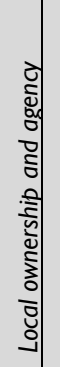 & 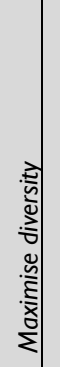 & 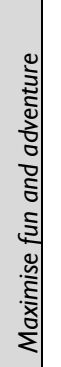 & 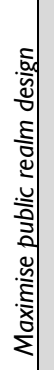 & 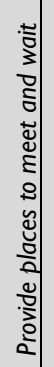 & 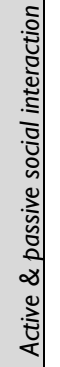 & 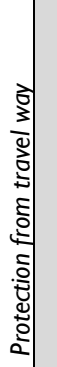 & 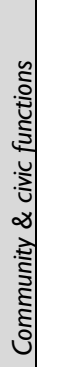 & 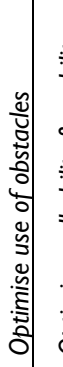 & 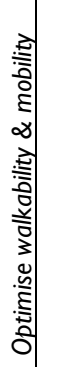 & 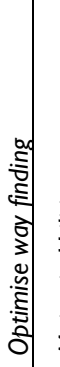 & 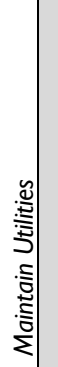 & 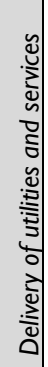 \\
\hline \multicolumn{26}{|l|}{ VALUES \& PRIORITY MEASURES } \\
\hline Engaging design elements & O & O & O & O & $\mathrm{O}$ & O & & & & & & 0 & O & & 0 & & & $\mathrm{O}$ & & 0 & $\mathrm{O}$ & & $\mathrm{O}$ & & \\
\hline Communal space & $\mathrm{O}$ & & & & & & & & & & 0 & $\mathrm{O}$ & o & 0 & 0 & & 0 & 0 & & $\mathrm{O}$ & $\mathrm{O}$ & & $\mathrm{O}$ & $\mathrm{O}$ & $\mathrm{O}$ \\
\hline Connections to nature & & $\mathrm{O}$ & 0 & $\mathrm{O}$ & 0 & 0 & & $\mathrm{O}$ & $\mathrm{O}$ & & 0 & & & 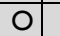 & 0 & & & 0 & & & $\mathrm{O}$ & $\mathrm{O}$ & & & \\
\hline Community connectedness & & 0 & $\mathrm{O}$ & $\mathrm{O}$ & $\mathrm{O}$ & 0 & & & & & $\mathrm{O}$ & $\mathrm{O}$ & 0 & 0 & 0 & & $\mathrm{O}$ & 0 & & O & & $\mathrm{O}$ & $\mathrm{O}$ & 0 & 0 \\
\hline Optimise transition between spaces & & 0 & 0 & $\mathrm{O}$ & 0 & 0 & 0 & $\mathrm{O}$ & & $\mathrm{O}$ & 0 & & 0 & & 0 & $\mathrm{O}$ & & & $\mathrm{O}$ & & $\mathrm{O}$ & $\mathrm{O}$ & $\mathrm{O}$ & & \\
\hline Enable individuality of design & & 0 & 0 & $\mathrm{O}$ & 0 & 0 & & $\mathrm{O}$ & & & 0 & $\mathrm{O}$ & 0 & 0 & $\mathrm{O}$ & & & $\mathrm{O}$ & & 0 & & $\mathrm{O}$ & $\mathrm{O}$ & & \\
\hline Optimise achievability & & & & & & & & $\mathrm{O}$ & & & $\mathrm{O}$ & & 0 & & & $\mathrm{O}$ & & & & & & & & $\mathrm{O}$ & 0 \\
\hline Physical comfort & 0 & 0 & 0 & $\mathrm{O}$ & $\mathrm{O}$ & $\mathrm{O}$ & $\mathrm{O}$ & & $\mathrm{O}$ & & & & & & & & 0 & & $\mathrm{O}$ & & $\mathrm{O}$ & $\mathrm{O}$ & $\mathrm{O}$ & & $\mathrm{O}$ \\
\hline Perceived safety & & & & & & & $\mathrm{O}$ & $\mathrm{O}$ & & & & 0 & & & & & 0 & & $\mathrm{O}$ & & $\mathrm{O}$ & $\mathrm{O}$ & $\mathrm{O}$ & & \\
\hline Actual safety & & & & & & & 0 & & $\mathrm{O}$ & $\mathrm{O}$ & & & & & & 0 & & & 0 & & O & 0 & & & 0 \\
\hline Optimise universal design & 0 & & & & & & & & 0 & & & & & 0 & & 0 & & 0 & & & 0 & 0 & 0 & & 0 \\
\hline Adherence to built environment standards & & & & & & & & & 0 & & & & & & & 0 & & & & & & & & 0 & 0 \\
\hline Adherence to rules and laws & & & & & & & 0 & & & & & & & & & & & 0 & & 0 & & & 0 & 0 & \\
\hline Integrate community values & & & & & & & & & & & 0 & 0 & 0 & 0 & 0 & 0 & 0 & 0 & & 0 & & & & & \\
\hline
\end{tabular}

In considering the linkages from the perspective of the priority measures many of these are significantly supported by the twenty-five (25) functions. For example, the priority measure for 'community connectedness' is achieved via seventeen (I7) functions.

Significantly fourteen (14) of those activities ceased under lockdown, vastly diminishing the capacity of this measure to support all three (3) top level purposes it is connected 
to - a healthy and happy community; an inclusive and connected community; and a healthy and active individual.

In a similar way the priority measure of engaging design elements relies on thirteen (I3) functions, of which eleven (II) were unavailable in COVID-19 lockdown. The following priority measures also lost more than $70 \%$ of their supporting functions - connections to nature; individuality of design; communal space and integrate community values. While the measures of optimise transition between spaces; optimise achievability; and physical comfort also lost more than $50 \%$ of their supporting functions. The results highlight a significant deterioration of the capacity for these measures to support and achieve the higher order purposes of the public space system.

Conversely the model reveals some measures were largely unaffected by lockdown including adherence to built environment standards; and actual safety, each only losing one (I) function. This reveals that these measures are supported by functions that are largely built into the public space and remain regardless of lockdown restrictions, e.g. 'minimise surface water ponding'; 'protection from the travel way'

\section{Limitations}

Limitations of this study are related to its exploratory nature and application within the singular context of Queensland, Australia. Further insights would be gained from additional public spaces case studies from other countries and cultural contexts. In addition, only the first phase of CWA has been applied, and as an actor and event independent approach, there would be much to gain by exploring the implications of different public space users, times of day, and seasonal conditions.

\section{The impacts on design}

The WDA assists in establishing the cumulative impact of the removal of multiple supporting functions, in the capacity of the priority measures to then support the overall purposes. In many ways we already knew this to be true; individuals and communities craved the activities that public space afforded them which were suddenly no longer possible. However, what the systems model reveals is how the limits of those activities resulted in us feeling individually and collectively less happy and healthy, and without these important urban spaces to share and dwell within, often less connected as a community.

This analysis was exploratory in nature, and sought to offer new perspectives on the emerging challenges facing the design and usability of public space. It is offered to assist in investigating the increasing complexity of our urban environments. This paper has outlined some of the contributory factors associated with the individual and community impacts of lockdown on existing public space.

Going forward, the intention is that a systems viewpoint may also assist in exploring the possibilities to reinstate some of those functions and conceive opportunities for new functions even under lockdown. If we move from the intention and values of public space, at the top of WDA, to the design and deployment of objects and resources, at the bottom, it is possible to consider new design outcomes. Some of the functions lost in the COVID-19 lockdown could be brought back into the urban realm in a safe way as a consequence of different design approaches and prioritising variations in the intensity of human interaction in urban public spaces. For instance, the recovery of community wellbeing would benefit from a revision of levels of urbanity, as different types of space 
can promote a sense of being together while phisically apart, allowing community members in the same place in a safe way while supporting functions such as local businesses and community cohesion. In this regard, the design and establishment of both social and retreat spaces can provide evidence of how urban spaces can function based on different configurations (street-based and landscape-based spaces and physical objects) consequently affording and enabling urbanity through different types of human interaction (Tavares et al., 2019; Tavares \& Swaffield, 2017). The implementation of social and retreat spaces which offer different 'object related processes' and 'physical objects' may enable 'safe behaviour' and 'offer diversity in spaces', as necessary functions in post COVID- 19 public spaces.

\section{References}

Abedi, M., Mofidi, M., \& Behzadfar, M. (20II). Investigation role of sensory stimulus in perception of urban spaces. International Journal of Academic Research, 3(2), 20I-205.

Australian Broadcasting Corporation (ABC). (2020). Massive boost to outdoor exercise in Sydney's green spaces during coronavirus, survey finds. Retrieved from: https://www.abc.net.au/news/2020-06-28/sydneys-green-space-use-booms-duringcovid-

$19 / 12400104$ ? utm_source=abc_news\&utm_medium=content_shared\&utm_content=mail\&ut $\mathrm{m}$ campaign $=\mathrm{abc}$ news

Australian Government (20II). Creating Places for People — an urban design protocol for Australian cities. Infrastructure Australia. Retrieved from https://www.infrastructureaustralia.gov.au/publications/creating-places-people-urban-designprotocol-australian-cities

Bisantz, A. M., Roth, E., Brickman, B., Gosbee, L. L., Hettinger, L., \& McKinney, J. (2003). Integrating cognitive analyses in a large-scale system design process. International Journal of Human-Computer Studies, 58, I77-206.

Burton, E., Mitchell, L., \& Lynne Mitchell, M. E. S. (2006). Inclusive urban design: Streets for life. Elsevier.

Cornelissen, M., Salmon, P. M., \& Young, K. L. (20I3). Same but Different? Understanding Road User Behaviour at Intersections Using Cognitive Work Analysis. Theoretical Issues in Ergonomics Science, 14(6), 592-615.

Degen, M. M., \& Rose, G. (2012). The sensory experiencing of urban design: the role of walking and perceptual memory. Urban studies, 49(I5), 327I-3287.

Freeman, S., \& Eykelbosh, A. (2020). COVID-19 and outdoor safety: Considerations for use of outdoor recreational spaces. National Collaborating Centre for Environmental Health. Public Health Agency of Canada.

Grahn, P., \& Stigsdotter, U. K. (2010). The relation between perceived sensory dimensions of urban green space and stress restoration. Landscape and urban planning, 94(3-4), 264-275.

Jenkins, D. P., Salmon, P. M., Stanton, N. A., \& Walker, G. H. (2010). A New Approach for Designing Cognitive Artefacts to Support Disaster Management. Ergonomics, 53(3), 617-635.

Jenkins, D. P., Stanton, N. A., Salmon, P. M., \& Walker, G. H. (2009). Cognitive Work Analysis: Coping with Complexity. Ashgate Publishing Limited.

Lees, L. (2010). Planning urbanity? Environment and Pla nning A, 42(I0), 2302-2308.

Low, S., Taplin, D., \& Scheld, S. (2009). Rethinking urban parks: Public space and cultural diversity. University of Texas Press. 
Exploring the impact of COVID-19 lockdown on public spaces through a systems modelling approach

Lévy J (1997) La mesure de l'urbanité. Urbanisme, 296, 58-6I.

Missen, L., Stevens, N. J., \& Salmon, P. M. (2017). A Sociotechnical Systems Analysis Approach to Playground Design. Proceedings from Contemporary Ergonomics \& Human Factors, 35-42.

Montgomery J (1998) Making a city: Urbanity, vitality and urban design. Journal of Urban Design 3(I). 93-I |6. DOI: 10.1080//35748098087244I8.

Naikar, N. (2013). Work Domain Analysis: Concepts, Guidelines, and Cases. CRC Press.

Patorniti, N. P., Stevens, N. J., \& Salmon, P. M. (20I7). A Systems Approach to City Design: Exploring the Compatibility of Sociotechnical Systems. Habitat International, 66, 42-48.

Patorniti, N. P., Stevens, N. J., \& Salmon, P. M. (2018). A Sociotechnical Systems Approach to Understand Complex Urban Systems: A Global Transdisciplinary Perspective. Human Factors and Ergonomics in Manufacturing \& Service Industries, 28(6), 28I-296.

Queensland Health (2020). Queensland Government Health Department, Restrictions in Queensland. Brisbane, Australia. Retrieved from: https://www.qld.gov.au/health/conditions/health-alerts/coronavirus-covid-19/currentstatus/public-health-directions

Rasmussen, J., Pejtersen, A. M., \& Goodstein, L. P. (1994). Cognitive systems engineering. Wiley.

Salmon, P. M., Read, G. J., \& Stevens, N. J. (2016). Who is in Control of Road Safety? A STAMP Control Structure Analysis of the Road Transport System in Queensland, Australia. Accident Analysis \& Prevention, 96, 140-151.

Salmon, P. M., Walker, G. H., \& Stanton, N. A. (2016). Pilot Error Versus Sociotechnical Systems Failure: A Distributed Situation Awareness Analysis of Air France 447. Theoretical Issues in Ergonomics Science, I 7(1), 64-79.

Stevens, N. J. (2016). Sociotechnical Urbanism: New Systems Ergonomics perspectives on Land Use Planning and Urban Design. Theoretical Issues in Ergonomics Science, I 7(4), 443-45I.

Stevens, N. J., \& Salmon, P. M. (20I4). Safe Places for Pedestrians: Using Cognitive Work Analysis to Consider the Relationships between the Engineering and Urban Design of Footpaths. Accident Analysis \& Prevention, 72, 257-266.

Stevens, N. J., \& Salmon, P. M. (2015). New Knowledge for Built Environments: Exploring Urban Design from Socio-technical System Perspectives. International Conference on Engineering Psychology and Cognitive Ergonomics, 200-2II.

Stevens, N. J., Salmon, P. M., Walker, G. H., \& Stanton, N. A. (2018). Human Factors in Land Use Planning and Urban Design: Methods, Practical Guidance, and Applications. CRC Press.

Tavares, S. G., \& Swaffield, S. (2017). Urban Comfort in a Future Compact City: Analysis of Open space Qualities in the Rebuilt Christchurch Central City. Landscape Review, I7(2), 523. https://journals.lincoln.ac.nz/index.php//r/article/view/I 035

Tavares, S. G., Swaffield, S., \& Stewart, E. J. (2019). A case-based methodology for investigating urban comfort through interpretive research and microclimate analysis in post-earthquake Christchurch, New Zealand. Environment and Planning B: Urban Analytics and City Science, 46(4), 73I-750. https://doi.org/I0.1 I77/23998083 I77253/8

Van Diepen AML and Musterd S (2009) Lifestyles and the city: connecting daily life to urbanity. Journal of Housing and the Built Environment 24: 33I-345.

Vicente, K. J. (1999). Cognitive Work Analysis: Toward Safe, Productive, and Healthy Computer-Based Work. Lawrence Erlbaum Associates.

Walker, G. H., Stanton, N. A., Salmon, P. M., \& Jenkins, D. P. (2008). A Review of Sociotechnical Systems Theory: A Classic Concept for new Command and Control Paradigms. Theoretical Issues in Ergonomics Science, 9(6), 479-499. 